\title{
E-Business system development: review on methods, design factors, techniques and tools with an extensive case study for secure online retail selling industry H. Saini ${ }^{1}$, D. Saini ${ }^{2}$ and N. Gupta ${ }^{3}$ \\ ${ }^{1}$ Department of Information Technology, Orissa Engineering College, Bhubaneswar-752050, India \\ ${ }^{2}$ Faculty of Computing and Information Technology, Sohar University, Sultanate of Oman. \\ ${ }^{3}$ Birla Institute of Technology, Pilani, India \\ hemraj1977@yahoo.com; dineshkumarsaini74@yahoo.com²; nirmal@bits-pilani.ac.in ${ }^{3}$
}

\begin{abstract}
The potential of the internet economy demands newer business models and all-round information systems. The cross-enterprise business process requires high co-ordination of the customers and the suppliers, taking less time and high outcomes. To exploit this potential of the internet economy, companies are involved in a painstaking process of designing its information
\end{abstract} systems for future development.

A variety of techniques available to implement the ecommerce includes EDI, electronic markets and Internet e-business. These techniques are implemented using various technologies like WAP, Bluetooth, Mobile computing and many others.

Developer tools are required to implement the technologies includes various web tools like J2EE, ASP, Visual Basic, WAP (WML/WSL), DHTML, C++, Powerbuilder, Informix/4GL. It also involves web/application servers like commerce server by Microsoft, Allaire JRun, IBM websphere and Integration platforms like Microsoft Biztalk servers, DataJunction adapters, EAI, etc.

At the end, the paper gives a case study for Secure Online Retail Selling Industry which represents how a traditional selling system can convert itself into ebusiness system with a better performance.

Keywords: E-business, B2B, B2C, C2C, Intra-business, e-business development methodologies.

Introduction

Over the last decade the focus of the information technology industry has moved towards development for the World Wide Web (WWW). Information systems using WWW technology, delivered by an Intranet or via the Internet, are now prevalent throughout world. Within a country, a wide variety of organizations are deploying information systems onto the WWW, including banks, government departments and other service providers. They are using the WWW as a strategic business tool, supporting their existing operations or providing a lowcost solution for delivering a new product or service line. Due to this, the business on the Internet is growing with a great speed, which results in the form of e-commerce.

\section{Types of e-commerce}

Business-to-Consumer (B2C): It describes activities of businesses serving end consumers with products and/or services.

An example of a B2C transaction would be a person buying a pair of shoes from a retailer. The transactions that led to the shoes being available for purchase, that is the purchase of the leather, laces, rubber, etc. as well as the sale of the shoe from the shoemaker to the retailer would be considered (B2B) transactions. Other examples of B2C e-commerce grouped as: 1) Pre-sale: It includes Information seeking, marketing presence and On-line catalogue. 2) Sale execution: It includes On-line catalogue and On-line ordering. 3) Sale settlement: It is related to On-line payment. 4) After-sale: Customer relationship management (CRM) is the important part of this stage.

Business-to-Business (B2B): It is a term commonly used to describe commerce transactions between businesses like the one between a manufacturer and a wholesaler or a wholesaler and a retailer i.e. both the buyer and the seller are business entity. This is unlike business-toconsumers (B2C) which involve a business entity and end consumer, or business-to-government (B2G) which involve a business entity and government.

The volume of B2B transactions is much higher than the volume of $\mathrm{B} 2 \mathrm{C}$ transactions. The primary reason for this is that in a typical supply chain there will be many B2B transactions involving subcomponent or raw materials, and only one B2C transaction, specifically sale of the finished product to the end customer. For example, an automobile manufacturer makes several B2B transactions such as buying tires, glass for windshields, and rubber hoses for its vehicles. The final transaction, a finished vehicle sold to the consumer, is a single (B2C) transaction.

Consumer-to-Consumer (or C2C): It involves the electronically-facilitated transactions between consumers through some third party. A common example is the online auction, in which a consumer posts an item for sale and other consumers bid to purchase it; the third party generally charges a flat fee or commission. The sites are only intermediaries, just there to match consumers. They do not have to check quality of the products being offered.

Intra-business: E-commerce activities conducted within an organization in between a business and its employees, in between units within the business or among employees in the same business are known as intra-business. Its most popular form is business-toemployees (B2E) which is an intra-business in which an organization delivers products or services to its employees in any of the following form:

- Training and education provided over intranets
Saini et al. Indian J.Sci.Technol. 
- Electronically order supplies and material needed for work

- Buy discounted insurance, travel packages, etc., on corporate intranet

- Corporate stores sell company's products at a discount

- Businesses disseminate information on the intranet

- Employees manage fringe benefits take classes and more

There are certain processes such as re-engineering to improve efficiency, integration of existing systems to support cross-organisational processes, workflow models, attempt to present a comprehensive and cogent taxonomy of business models observable on the web. The proposed taxonomy is not meant to be exhaustive or definitive. Internet business models continue to evolve. New and interesting variations can be expected in the

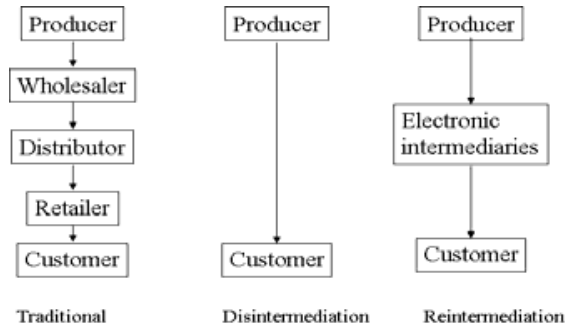

Fig. 1. Information flow in business future. The basic categories of business models include: 1) brokerage, 2) advertising, 3) infomediary , 4) merchant, 5) manufacturer (direct), 6) affiliate, 7) community, 8) subscription and 9) utility.

The models are implemented in a variety of ways, as described below with examples. Moreover, a firm may knowledge management etc. due to that the intrabusiness becomes e-Business.

Business transformation

In the e-business it is important to know how the information flows from producer to its customer. In general there are three ways of flow of information: 1) traditional, 2) disintermediation and 3) reintermediation.

Fig. 1 represents the view of flow of information in all three ways mentioned above. In traditional the information start from producer which proceeds to wholesaler, wholesaler to distributor, distributor to retailer and finally retailer to customer.

In disintermediation the information directly flow from producer to customer, in this there is no mediator.

In the third way, i.e. reintermediation, the information flows from producer to some electronic intermediaries and then to customs.

Here, for the e-business, it is obvious that we have to use Reintermediation way of flow of product information as the electronic intermediaries are coming into the picture.

\section{E-business models}

In the corporate world every one wants to be the leader of their world. To get the Organizational Leadership it is necessary to adapt to Corporate Knowledge and Information Tacit Assets. The organization which gets the most will become the leader of their world. Fig.2 shows that the leadership can

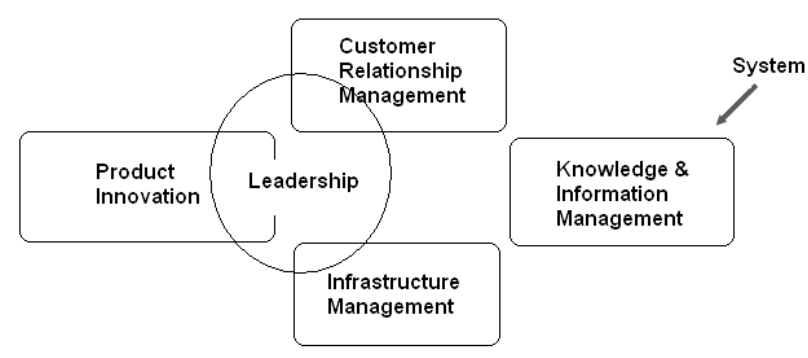

rıg. 2. Hhases to achieve the leadership combine several different models as part of its overall Internet business strategy. For example, it is not uncommon for content driven businesses to blend advertising with a subscription model.

Business models have taken on greater importance recently as a form of intellectual property that can be protected with a patent. Indeed, business models (or more broadly speaking, "business methods") have fallen increasingly within the realm of patent law. A number of business method patents relevant to e-commerce have been granted. But what is new and novel as a business model is not always clear. Some of the more noteworthy patents may be challenged in the courts.

Brokerage model. Brokers are market-makers: they bring buyers and sellers together and facilitate transactions. Brokers play a frequent role in business-to-business (B2B), business-to-consumer (B2C), or consumer-toconsumer (C2C) markets. Usually a broker charges a fee or commission for each transaction it enables. The formula for fees can vary.

be achieved by four phases: 1) by the management of the collected knowledge, 2) by the innovation of their product, 3 ) by well management of infrastructure and 4) by making the healthy customer relationship.

To achieve this leadership the e-business must be having some working business models (Gordijn \& Akkermans, 2001; Pateli \& Giaglis, 2003). These business models have been defined and categorized in many different ways as mentioned below. This is one
Brokerage models may include: Marketplace exchange: It offers a full range of services covering the transaction process, from market assessment to negotiation and fulfillment. Exchanges operate independently or are backed by an industry consortium. Buy/Sell fulfillment. It takes customer orders to buy or sell a product or service, including terms like price and delivery. Demand collection system: The patented "nameyour-price" model pioneered by Priceline.com. Prospective buyer makes a final (binding) bid for a specified good or service, and the broker arranges fulfillment. Auction broker. It conducts auctions for sellers (individuals or merchants). Broker charges the seller a listing fee and commission scaled with the value of the transaction. Auctions vary widely in terms of the offering and bidding rules. Transaction broker. It provides a third- 
party payment mechanism for buyers and sellers to settle a transaction. Distributor. It is a catalog operation that connects a large number of product manufacturers with volume and retail buyers. Broker facilitates business transactions between franchised distributors and their trading partners. Search agent. A software agent or "robot" used to search-out the price and availability for a good or service specified by the buyer, or to locate hard to find information. Virtual marketplace: A virtual mall is a hosting service for online merchants that charges setup, monthly listing, and/or transaction fees. It may also provide automated transaction and relationship marketing services.

Advertising model. The web advertising model is an extension of the traditional media broadcast model. The broadcaster, in this case, a web site, provides content (usually, but not necessarily, for free) and services (like email, IM, blogs) mixed with advertising messages in the form of banner ads. The banner ads may be the major or sole source of revenue for the broadcaster. The broadcaster may be a content creator or a distributor of content created elsewhere. The advertising model works best when the volume of viewer traffic is large or highly specialized.

Portal. It is usually a search engine that may include varied content or services. A high volume of user traffic makes advertising profitable and permits further diversification of site services. A personalized portal allows customization of the interface and content to the user. A niche portal cultivates a well-defined user demographic.

Classifieds. They list items for sale or wanted for purchase. Listing fees are common, but there also may be a membership fee.

User registration: It is content-based site that is free to access but require users to register and provide demographic data. Registration allows inter-session tracking of user surfing habits and thereby generates data of potential value in targeted advertising campaigns.

Query-based paid placement. It sells favorable link positioning (i.e., sponsored links) or advertising keyed to particular search terms in a user query.

Contextual avertising / behavioral marketing. They are freeware developers who bundle adware with their product. For example, a browser extension that automates authentication and form fill-ins, also delivers advertising links or pop-ups as the user surfs the web. Contextual advertisers can sell targeted advertising based on an individual user's surfing activity.

Content-Targeted advertising. It is pioneered by Google; it extends the precision of search advertising to the rest of the web. Google identifies the meaning of a web page and then automatically delivers relevant ads when a user visits that page.

Intromercials: These are animated full-screen ads placed at the entry of a site before a user reaches the intended content.

Popular article

COIndian Society for Education and Environment (iSee)
Ultramercials: These are interactive online ads that require the user to respond intermittently in order to wade through the message before reaching the intended content.

\section{Infomediary model}

Data about consumers and their consumption habits are valuable, especially when that information is carefully analyzed and used to target marketing campaigns. Independently collected data about producers and their products are useful to consumers when considering a purchase. Some firms function as infomediaries (information intermediaries) assisting buyers and/or sellers understand a given market.

Advertising networks. They are used to feed banner ads to a network of member sites, thereby enabling advertisers to deploy large marketing campaigns. Ad networks collect data about web users that can be used to analyze marketing effectiveness.

Audience measurement services: They are online audience market research agencies.

Incentive marketing. It is a customer loyalty program that provides incentives to customers such as redeemable points or coupons for making purchases from associated retailers. Data collected about users is sold for targeted advertising.

Metamediary. It facilitates transactions between buyer and sellers by providing comprehensive information and ancillary services, without being involved in the actual exchange of goods or services between the parties.

\section{Merchant model}

This model deals with the goods and services of wholesalers and retailers. At this sales may be made based on list prices or through auction.

Virtual merchant. An e-tailer is a retail merchant that operates solely over the web.

Catalog merchant. It is a mail-order business with a webbased catalog. Combines mail, telephone and online ordering.

Click and mortar. It is a traditional brick-and-mortar retail establishment with web storefront.

Bit vendor. A merchant that deals strictly in digital products and services and, in its purest form, conducts both sales and distribution over the web.

Manufacturer (direct) model

The manufacturer or "direct model", it is predicated on the power of the web to allow a manufacturer (i.e., a company that creates a product or service) to reach buyers directly and thereby compress the distribution channel. The manufacturer model can be based on efficiency, improved customer service, and a better understanding of customer preferences.

Purchase: The sale of a product in which the right of ownership is transferred to the buyer.

Lease: It is used in exchange for a rental fee; the buyer receives the right to use the product under a "terms of use" agreement. The product is returned to the seller upon expiration or default of the lease agreement. One

\section{"e-Business" \\ http://www.indjst.org}

Saini et al.

Indian J.Sci.Technol. 
type of agreement may include a right of purchase upon expiration of the lease.

License: The sale of a product that involves only the transfer of usage rights to the buyer, in accordance with a "terms of use" agreement. Ownership rights remain with the manufacturer (e.g., with software licensing).

Brand integrated content. It is used in contrast to the sponsored-content approach (i.e., the advertising model), brand-integrated content is created by the manufacturer itself for the sole basis of product placement.

Affiliate model

In contrast to the generalized portal, which seeks to drive a high volume of traffic to one site, the affiliate model, provides purchase opportunities wherever people may be surfing. It does this by offering financial incentives (in the form of a percentage of revenue) to affiliated partner sites. The affiliates provide purchase-point clickthrough to the merchant. It is a pay-for-performance model, if an affiliate does not generate sales; it represents no cost to the merchant. The affiliate model is inherently well-suited to the web, which explains its popularity. Variations include banner exchange, pay-per-click, and revenue sharing programs.

Banner exchange: It is a trade's banner placement among a network of affiliated sites.

Pay-per-click. A site that pays affiliates for a user clickthrough.

Revenue sharing. It offers a percent-of-sale commission based on a user click-through in which the user subsequently purchases a product.

\section{Community model}

The viability of the community model is based on user loyalty. Users have a high investment in both time and emotion. Revenue can be based on the sale of ancillary products and services or voluntary contributions; or revenue may be tied to contextual advertising and subscriptions for premium services. The Internet is inherently suited to community business models and today this is one of the more fertile areas of development, as seen in rise of social networking.

Open source: Software developed

collaboratively by a global community of programmers who share code openly. Instead of licensing code for a fee, open source relies on revenue generated from related services like systems integration, product support, tutorials and user documentation.

Open content. Openly accessible content developed collaboratively by a global community of contributors who work voluntarily.

Public broadcasting. It is an user-supported model used by not-for-profit radio and television broadcasting extended to the web. Communities of users support the site through voluntary donations.

Popular article

COIndian Society for Education and Environment (iSee)
Social networking services. The sites that provide individuals with the ability to connect to other individuals along a defined common interest (professional, hobby, romance). Social networking services can provide opportunities for contextual advertising and subscriptions for premium services.

\section{Subscription model}

Users are charged a periodic (daily, monthly or annual) fee to subscribe to a service. It is not uncommon for sites to combine free content with "premium" (i.e., subscriberor member-only) content. Subscription fees are incurred irrespective of actual usage rates. Subscription and advertising models are frequently combined.

Content services: They provide text, audio, or video content to users who subscribe for a fee to gain access to the service.

Person-to-person networking services: They are conduits for the distribution of user-submitted information, such as individuals searching for former schoolmates.

Trust services: They come in the form of membership associations that abide by an explicit code of conduct, and in which members pay a subscription fee.

Internet services providers: They offer network connectivity and related services on a monthly subscription.

\section{Utility model}

The utility or "on-demand" model is based on metering usage, or a "pay as you go" approach. Unlike subscriber services, metered services are based on actual usage rates. Traditionally, metering has been used for essential services (e.g., electricity water, long-distance telephone services). Internet service providers (ISPs) in some parts of the world operate as utilities, charging customers for connection minutes, as opposed to the subscriber model common in the western countries.

Metered usage: It measures and bills users based on actual usage of a service.

Metered subscriptions: It allows subscribers to purchase access to content in metered portions (e.g., numbers of pages viewed).

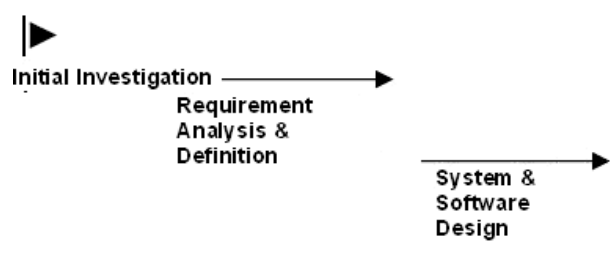

Fig.3. Stages of waterfall model

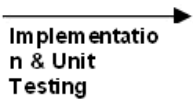

Acceptable system development methodologies

System development methodologies are based on basic software engineering models, such as waterfall model, prototype model and spirals model (Metropolis et al., 1980; Budde et al., 1984; Walt Scacchi, 2001; Ricky Don Preuninger, 2006). Important pros and cons are discussed in the following subsections.

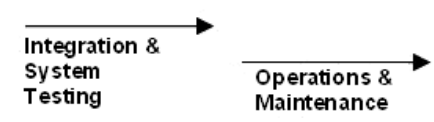




\section{Waterfall}

There are various software development approaches defined and designed which are used/employed during development process of software, these approaches are also referred as "Software development process models". Each process model follows a particular life cycle in order to ensure success in process of software development.

One such approach/process used in Software Development is "The Waterfall model", shown in Fig.3. Waterfall approach was first Process model to be introduced and followed widely in Software Engineering to ensure success of the project. In "The Waterfall" approach, the whole process of software development is divided into separate process phases. The phases in Waterfall model are: Requirement specifications phase, software design, implementation and testing \& maintenance. All these phases are cascaded to each other so that second phase is started as and when defined set of goals are achieved for first phase and it is signed off, so the name "Waterfall model". All the methods and processes undertaken in Waterfall model are more visible.

The stages of "The Waterfall model" are:

Requirement analysis \& definition: All possible requirements of the system to be developed are captured in this phase. Requirements are set of functionalities and constraints that the end-user (who will be using the system) expects from the system. The requirements are gathered from the end-user by consultation, these requirements are analyzed for their validity and the possibility of incorporating the requirements in the system to be development is also studied. Finally, a requirement specification document is created which serves the purpose of guideline for the next phase of the model.

System \& software design: Before a starting for actual coding, it is highly important to understand what we are going to create and what it should look like? The requirement specifications from first phase are studied in this phase and system design is prepared. System design helps in specifying hardware and system requirements and also helps in defining overall system architecture. The system design specifications serve as input for the next phase of the model.

Implementation \& unit testing. On receiving system design documents, the work is divided in modules/units and actual coding is started. The system is first developed in small programs called units, which are integrated in the next phase. Each unit is developed and tested for its functionality; this is referred to as unit testing. Unit testing mainly verifies if the modules/units meet their specifications.

Integration \& system testing. As specified above, the system is first divided in units which are developed and tested for their functionalities. These units are integrated into a Popular article CIndian Society for Education and Environment (iSee)

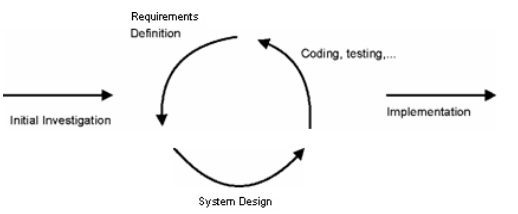

Fig.4. Iterative and non-iterative steps in prototyping

"e-Business"

http://www.indjst.org
Vol.2 No 5 (May 2009)

ISSN: 0974- 6846 complete system during Integration phase and tested to check if all modules/units coordinate between each other and the system as a whole behaves as per the specifications. After successfully testing the software, it is delivered to the customer.

Operations \& maintenance: This phase of "The Waterfall model" is virtually never ending phase (very long). Generally, problems with the system developed (which are not found during the development life cycle) come up after its practical use starts, so the issues related to the system are solved after deployment of the system. Not all the problems come in picture directly but they arise time to time and needs to be solved; hence this process is referred as Maintenance.

There are some disadvantages of the Waterfall model. 1) As it is very important to gather all possible requirements during the Requirement Gathering and Analysis phase in order to properly design the system, not all requirements are received at once, the requirements from customer goes on getting added to the list even after the end of "Requirement gathering and analysis" phase, this affects the system development process and its success in negative aspects. 2) The problems with one phase are never solved completely during that phase and in fact many problems regarding a particular phase arise after the phase is signed off, these results in badly structured system as not all the problems (related to a phase) are solved during the same phase. 3) The project is not partitioned in phases in flexible way. 4) As the requirements of the customer goes on getting added to the list, not all the requirements are fulfilled, this results in development of almost unusable system. These requirements are then met in newer version of the system; this increases the cost of system development.

\section{Prototyping}

It is an easily modified and extensible model (representation, simulation or demonstration) of a planned software system, likely including its interface and input/output functionality. The prototyping processes need many variations for the perfection of the function. Fig. 4 shows the iterative and non-iterative steps of the prototyping.

Some of the important iterations are:

- Perform customer needs analysis in a JAD session but leave requirements incomplete.

- Build a low-fidelity prototype to clarify initial requirements.

- Iterate (re-specify, re-design, re-evaluate) until the team, both users and developers, agree that the fidelity and completeness of the evolving prototype are sufficiently high.

- Freeze these specifications.

- Finish building the product exactly as prototyped.

- NOTE: The prototyping process experiences a series of 
birthdays while traditional software development experiences a series of deadlines.

The Fig. 5 shows how the iterations have to be performed to get the perfection in the prototyping system.

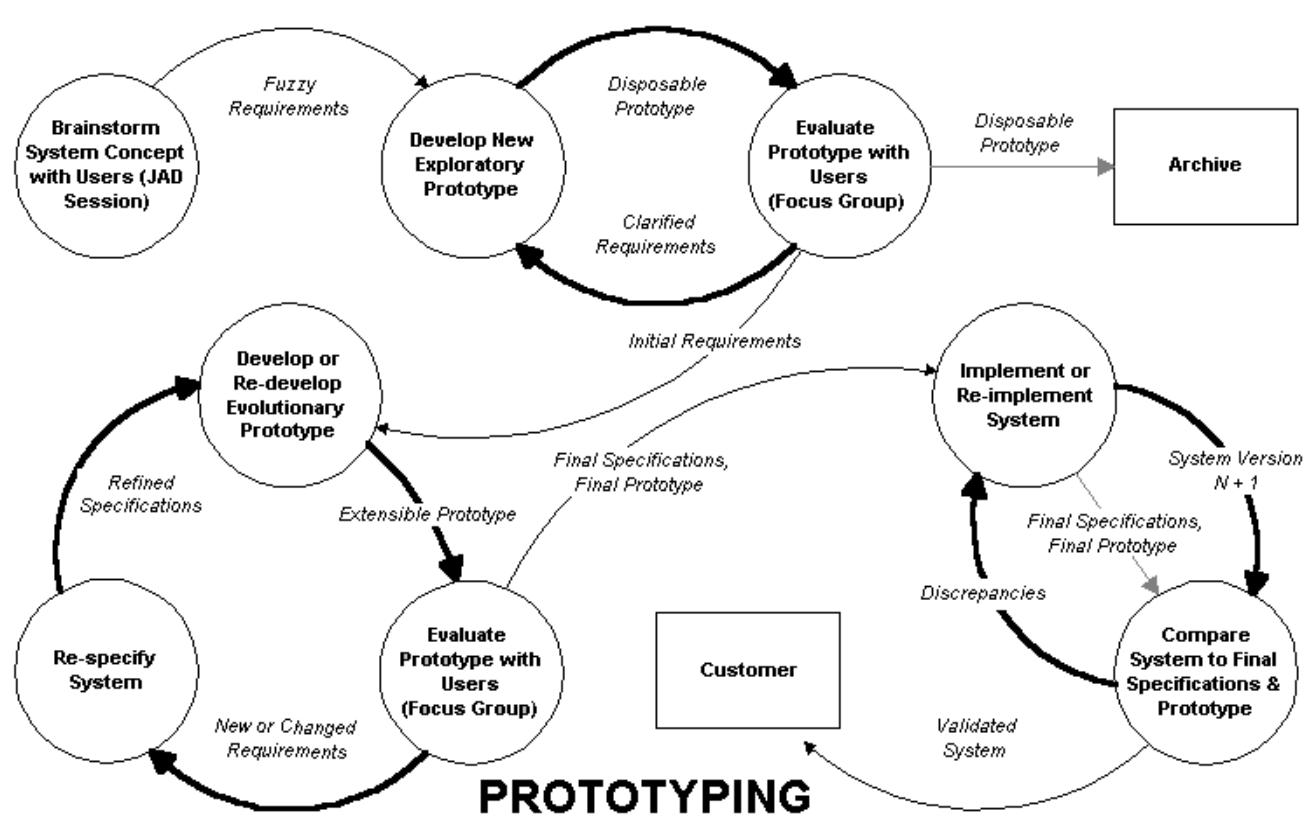

Fig. 5. Iteration to get perfection in prototyping

iteratively followed one after other in order to eliminate all the problems, which were faced in "The Waterfall model". Iterating the phases helps in understating the problems associated with a phase and dealing with those problems when the same phase is repeated next time, planning and developing strategies to be followed while iterating through the phases. The phases in "Spiral model" are: Plan: In this phase, the objectives, alternatives and constraints of the project are determined and are documented. The objectives and other specifications are fixed in order to decide which strategies/approaches to follow during the project life cycle.

Risk Analysis: This phase is the most important part of "Spiral model". In this phase all possible (and available) alternatives, which can help in developing a cost effective project are analyzed and

Spiral

In last article we discussed about "Waterfall model", which is one of the oldest and most simple model designed and followed during software development process. But "Waterfall model" has its own disadvantages such as there is no fair division of phases in the life cycle, not all the errors/problems related to a phase are resolved during the same phase, instead all those problems related to one phase are carried out in the next phase and are needed to be resolved in the next phase, this takes much of time of the next phase to solve them. The risk factor is the most important part, which affects the success rate of the software developed by following "The Waterfall model".

In order to overcome the cons of "The Waterfall model", it was necessary to develop a new Software Development Model, which could help in ensuring the success of software project. One such model was developed which incorporated the common methodologies followed in "The Waterfall model", but it also eliminated almost every possible/known risk factors from it. This model is referred as "The Spiral model" or "Boehm's model".

There are four phases in the "Spiral model" which are: Planning, Evaluation, Risk Analysis and Engineering, same as shown in Fig.6. These four phases are Popular article CIndian Society for Education and Environment (iSee) strategies are decided to use them. This phase has been added specially in order to identify and resolve all the possible risks in the project development. If risks indicate any kind of uncertainty in requirements, prototyping may be used to proceed with the available data and find out possible solution in order to deal with the potential changes in the requirements.

Engineering: In this phase, the actual development of the project is carried out. The output of this phase is passed through all the phases iteratively in order to obtain improvements in the same.

Customer evaluation: In this phase, developed product is passed on to the customer in order to receive customer's comments and suggestions which can help in identifying and resolving potential problems/errors in the software developed. This phase is very much similar to TESTING phase.

The process progresses in spiral sense to indicate iterative path followed, progressively

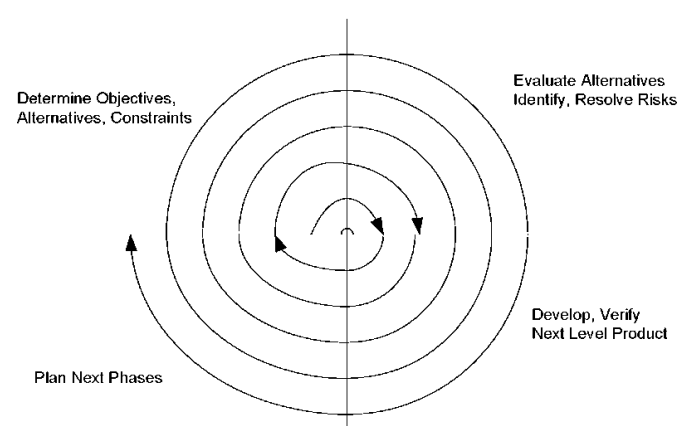

Fig.6. Spiral model

"e-Business"

http://www.indjst.org more complete software is built as we go on iterating through all four phases. The first iteration in this model is considered to be most important, as in the first iteration almost all possible risk factors, constraints, requirements are identified and in the next iterations all known strategies are used to bring up a complete software system. The radical dimensions 
indicate evolution of the product towards a complete system.

However, as every system has its own pros and cons, "The Spiral model" does have its pros and cons too. As this model is developed to overcome the disadvantages of the "Waterfall model", to follow "Spiral model", highly skilled people in the area of planning, risk analysis and mitigation, development, customer relation etc. are required. This along with the fact that the process needs to be iterated more than once demands more time and is somehow expensive task.

\section{E-Business system development}

In the first thing which comes to the mind in case of ebusiness system development is the requirements of an e-business system development and it benefits (Carmen Timofte, 2004). Once these two things are decided, then the next thing is e-business system development technical expertise for e-commerce development to implement it in the real world. Sub sections mentioned under are focusing on these points.

Requirements of an e-business

For a corporate e-business system can be required due to blow mentioned reasons:-

- An e-business system development provides value by organizing and streamlining operations, maximizing revenue opportunities and providing competitive advantage.

- An organization can maximize its return on investment (ROI) by choosing an e-business system development partner and service provider.

- The e-business system brings exceptional value to clients through reduced cost of e- business system development via the development centre, and outstanding reliability, quality and customer service.

Benefits of e-business system development

A good e-business system can benefit an organization in the following ways:

- A good e-business system developer provides value to clients due to the expertise in e-business system development, proven project management processes, quality management procedure, excellent technical resources and speed in customer response.

- Its e-business system development services are built on open, industry standard architectures made possible by enterprise component technologies like Java, and Microsoft. Net Framework, document oriented technologies like XML, and integration technologies such as messaging tools and middleware.

- It commits to providing clients with state-of-the-art ebusiness system development services by integrating technology, innovation and strategy with their business processes.

- It provides e-business system development services that engage customers, suppliers, distributors, employees and partners in a broader communications
Vol.2 No 5 (May 2009)

ISSN: 0974- 6846

web, allowing them to interact, collaborate, exchange data and conduct business online in a safe and efficient manner.

- It must believe that the hallmark is quality. Its resources and processes must be dedicated to ensuring that the e-business system development services are of the highest quality and scalability.

- Its e-business system development methodology allows spreading the development services across time zones, which allows customers to benefit from a 24-hour development cycle.

Technical expertise for e-business development

Currently the technical expertise for e-business development should include the following:

- Development: Java Server Pages (JSP), J2EE, Java, Active Server Pages (ASP), Visual Basic, COM/DCOM, PHP Scripting, XML, WAP (WML/WSL), DHTML, C++, PowerBuilder, Informix/4GL

- Databases: Microsoft SQL Server, Oracle, MySQL, Microsoft Access 2000, Sybase, Informix, DB2

- Web/Application servers: Microsoft Commerce Server, WebLogic, Allaire JRun, IBM WebSphere, Microsoft Internet Information Server

- Integration Platforms: Microsoft BizTalk Server, Microsoft Host Integration Server, DataJunction Adapters, EAI, WebMethods

E-business systems development methodology

E-business Systems must be having an easily attracted Development Methodology (Heydenrych \& Cloete, 2007). To choose a methodology one has to check its systematic arrangement, its appropriate reasons to use and compatibility with the characteristics of $\mathrm{e}$ business system.

Why Use Systematic Development Methodologies?

The following reasons are found to justify the use of systematic development methodologies:

- They are easier to understand systems by making a separation in between conceptual design, logical design, and physical design

- They design systems so that they are extendable and easily maintained

- They move toward automated design tools and dynamic page generation

- They are easier to manage development in the form of costs, time, task allocation, deliverables, etc.

- They overcome reliance on designers who constructed the system

- They are used to reduce risks associated with shortcuts and mistakes

- They are used to produce documentation that is consistent from one project to the next

- Finally, A word of caution should be maintained by considering that-
Saini et al. Indian J.Sci.Technol. 
- the systems development projects are not homogenous by nature

- there is not a single-best one-size-fits-all methodology

- in practice, most organizations are not committed to any single methodology, and mix and match as appropriate

Benefits of use systematic development methodologies

Use of Systematic Development Methodologies can benefic the corporate by the following manners-

- Reduced cycle time and / or reduced maintenance

- Increased productivity

- Higher quality systems

- Improved project management (Adam et al., 2007)

- time and cost estimates

- tracking

- resource utilization

Characteristics of development of web e-business system

- It should be having new usage patterns to ensure that the systems must be available at all times, meaning a 24 $\times 365$ system.

- It provides ease of use to its new customers according to their expectations such as more intuitive, easy to use, and foolproof.

- It shortened product life cycles to increase the productivity of the system.

- It is having clear visualization of information structure, easy for user to control, combination of hypermedia, non-linear exploration i.e. richer understanding of the structure and navigation components.

Fig.7 represents the whole process to develop the e-business system development methodology in a pictorial manner. It explains how to handle uncertain requirement, quick development, user-centered approach, object-oriented approach, and navigation taken into account with user requirement.

Case study for secure online selling industry: retail The business

It's a very old business, The fruit company sells retail and wholesale fruits through their Hope Circus based store in Alwar, Rajasthan. They also clean and pack the fruits in separate bags on the premises. The Fruit Company also retails a variety of vegetables. The business employs 7 staff.

\section{What was invited?}

The website was first developed in 2004 with modest expectations. As the customer experience was focused on visiting the shop, Ram Singh- the proprietor, could not imagine why people would buy products online without walking through the door! As the visitors to the website grew, more information and products were offered for sale. Customers can now view stock from the shop,
Vol.2 No 5 (May 2009)

ISSN: 0974- 6846 research fruits or vegetables and purchase via a Secure Payment Gateway. The site is also a valuable resource guide for all fruits and vegetables with an array of fruit links provided.

What is a secure payment gateway?

A payment system that allows customers to make it real-time and its secure credit card payments (Budde et al., 1984; Rosenberg Victor, 2002) across a website. The system encrypts credit card details to ensure that they remain secure from hacking and subsequent fraudulent use. "When I launched my website I said to my friends who had encouraged me to have a site, it would never work. However, it was so cheap to do that I thought I had nothing to lose. Fortunately, I have to admit that they were right."

\section{Ram Singh, owner}

Since 2008, over 300 orders have been received via the secure payment gateway in an 18 month period. Now, there is hardly a day that goes by without an order.

The fruit company website, complete with a Secure Payment Gateway has developed a significant revenue source from people who either shop online because they are unable to visit the shop or research their purchase online to then come and buy later.

How the technology works?

The Secure Payment Gateway works by processing the credit card details of the customer and passing the order via email to the Fruit Company for fulfillment. The process is outlined below:

1. The customer enters their order into the site including their credit card details.

2. The order is encrypted with the credit card payment being processed by the Secure Payment Gateway.

3. At the same time, an email is sent to the Fruit Company with the customer details and the items they wish to purchase.

4. Management instructs one of the staff to gather the items and prepare them to be posted.

5 . The order is delivered with the daily post by GATI.

Results

The fruit company website was launched 5 years ago and now it is a significant contributing channel to the business. The contribution to revenue measured against outgoings reveal an overall return on investment of RS. $37,20,000$.

Costs

Both establishment and ongoing costs were relatively low with the major expense being the establishment of the website at Rs. 1,00,000, amortized at Rs. 20,000 over five years.

The fruit company; a case study for secure online selling industry: retail 
The human resource to update the website has been Ram Singh's time but this is limited depending on how busy the business is. Overall, the upfront expenses came to Rs. $1,80,000$ during 2008 with operational expenses amounting to Rs. $1,00,000$.

One expense that the Fruit Company incurred wisely was the purchase of Anti-Virus software for Rs. 10,000. It is important to ask your Internet Service Provider or web developer about Internet Security, firewall and antivirus software when you set up your Internet access.

What is antivirus software?

It is a software program that scans computer systems for viruses. A virus is a computer program that is designed to replicate itself into the other programs stored in a computer. A virus can be transmitted as an attachment on an email, by downloading infected programming from other websites, or through a floppy disk or CD.

\section{Challenges and process change}

- The introduction of the website has not presented any major challenges nor changed processes within the offline retail store.

- One process that the Fruit Company has changed is the daily visits to the GATI office to dispatch the orders. This fulfillment of orders via GATI has been scheduled as part of the existing staff duties.

- The management of the fruit company found that the website volume is not yet large enough to warrant a dedicated staff member and given the solid return on investment is looking forward to the sales volume to grow further.

Future plans

The fruit company is planning on increasing the content to the website and providing even more detail about its fruits and vegetable items as well the supportive business of vegetable baskets. The fruit company is also actively working to improve their listings on Internet search engines as a method of increasing website traffic.

E-commerce profit and loss analysis (2008)

Additional Revenue from eCommerce (Rs.)

Direct Sales via the Internet 25,00,000

Indirect Sales via the Internet (estimated) 50,00,000

Gross Benefit from eCommerce 75,00,000

Less: Cost of Goods Sold 35,00,000

Net Profit for eCommerce 40,00,000

Less: Up Front Fixed Expenses

Website and Content management systems ${ }^{*} 20,000$

Anti-virus and Security software 10,000

Computer software 50,000

Computer hardware including modem 1,00,000

Total eCommerce Up Front Fixed Expenses 1,80,000

Less: E-Commerce Operational Expenses

Domain Charges (Web address) 10,000

Internet Service Provider/Hosting of Website 25,000

Technical Support 5,000

Postage Charges 30,000

Telecommunication Charges 30,000

Total eCommerce Operational Expenses 1,00,000

Total eCommerce Costs 2,80,000
Vol.2 No 5 (May 2009)

ISSN: 0974- 6846

Total eCommerce Benefit 37,20,000

*Total costs amortized over 5 years

The fruit company, Hope Circus, Alwar-301001

\section{Conclusion}

The paper gives detailed review on e-business development methods, and tools. Classical methods such as waterfall models, prototype and spiral models are discussed with their pros and cons extensively. Practical e-business development methodologies are not only discussed but also explained with their real world implementation steps. In addition recent technologies and tools are also suggested with their purpose in the ebusiness development process. Finally, a case study is given to understand the use of e-business in the small scale sectors. The data of the income, after implementing the e-business, are also given to present the effects of the e-business implementation over the traditional business.

\section{References}

1. Adam AM, Aderet A and Sadeh A (2007) Does ethics matter to e-consumers. J. Internet Commerce. 6 (2)1934.

2. Budde $R$, Kuhlenkamp $K$, Mathiassen $L$ and Zullighoven L (1984) Approaches to prototyping. Springer-Verlag New York, Inc., Secaucus, NJ.

3. Carmen Timofte (2004) Additional payment methods in e-commerce. Economy Informatics. 1-4, 30-32.

4. Gordijn J and Akkermans JM (2001) Designing and evaluating e-business models. IEEE Intelligent Systems - Intelligent e-Business, 16 (4), 11-17.

5. Heydenrych GJ and Cloete E (2007) ERP transition to ecommerce: training for a new methodology. Proc. of the 2007 Computer Science and IT Education Conf. pp: 323-334.

6. Metropolis N, Howlett J and Rota G-C (eds.) (1980) A history of computing in the twentieth century: a collection of essays. Academic Press, N.Y. pp: 3-9.

7. Pateli AG and Giaglis GM (2003) A framework for understanding and analyzing e-business models. In: Proc. of 16th Bled Electronic Commerce Conference eTransformation. Wigand, RT, Tan YH, Gricar J, Pucihar T and Lunar T (eds.), Kranj: Moderna Organizacija. pp: 329-348.

8. Ricky Don Preuninger (2006) The advantages of implementing software engineering process models, Ph.D. thesis.

9. Rosenberg Victor (2002) Information Literacy and Small Business. White Paper prepared for UNESCO, the U.S. National Commission on Libraries and Information Science, and the National Forum on Information Literacy, for use at the Information Literacy Meeting of Experts, Prague, The Czech Republic, July. Accessed 30 December 2004. Available at: http://www.nclis. gov/ libinter/infolitconf\&meet/papers/rosenbergfullpaper.pdf

10. Walt Scacchi (2001) Process models in software engineering. Marciniak JJ (ed.), Encyclopedia of software engineering, 2nd Edition, John Wiley and Sons, Inc, NY.
Popular article

COIndian Society for Education and Environment (iSee)
"e-Business"

http://www.indjst.org
Saini et al. Indian J.Sci.Technol. 